\title{
Aerial Radiometric and Video Measurements of Whitecap Coverage
}

\author{
Justin P. Bobak, Member, IEEE, William E. Asher, Member, IEEE, David J. Dowgiallo, and Magdalena D. Anguelova
}

\begin{abstract}
This paper presents the results of high-altitude microwave radiometric and video measurements in the presence of breaking waves made during the passage of Hurricane Dean on August 21, 2007, over the Gulf of Mexico. Previous measurements of foam fraction and radiometric brightness temperature have focused on the small scale, in which individual foam patches were of the same scale as the radiometer footprint. To work with data from spaceborne microwave radiometers, which have footprints on the scale of tens of kilometers, the knowledge of how the foam fraction sensitivity of brightness temperature scales when footprints increase from meters to kilometers is necessary. Video images of the sea surface recorded with a high-resolution monochrome digital camera were used to determine the foam fraction. Ocean-surface brightness temperature was measured with the Airborne Polarimetric Microwave Imaging Radiometer (APMIR) of the Naval Research Laboratory at frequencies of 6.6 [vertical and horizontal (VH) polarizations], $6.8(\mathrm{VH}), 7.2(\mathrm{VH})$, and $10.7 \mathrm{GHz}(\mathrm{V})$, with full polarimetric brightness temperatures measured at 19.35 and 37.0 GHz. Collocated nearly contemporaneous brightness temperatures were available from WindSat, Special Sensor Microwave Imager/Sounder, and Special Sensor Microwave/Imager satellite radiometer overpasses. Oceanographic and meteorological data were taken from buoys located along the flight track. There was good correlation between brightness temperatures measured with APMIR and satellite-borne radiometers with absolute differences largely within the expected uncertainty of the data. An analysis of the video imagery provided the fractional area coverage of the actively breaking waves on the ocean surface. The increase in brightness temperature from each of the microwave sensors was correlated with the whitecap coverage measured by the camera. The experiment not only serves as an important bridge between measurements made with spatial scales on the order of tens of meters and data collected from satellites with spatial scales of tens of kilometers but also provides guidance for improving future field measurements on this topic.
\end{abstract}

Index Terms-Foam fraction, microwave radiometry, sea foam, whitecap coverage, wind speed.

\section{INTRODUCTION}

B Y PRODUCING bubbles, sea spray, and sea-salt aerosols, large-scale breaking waves associated with whitecaps are involved in the planetary heat budget, air-sea gas exchange,

Manuscript received August 11, 2009; revised May 7, 2010 and September 9, 2010; accepted November 16, 2010. Date of publication February 9, 2011; date of current version May 20, 2011. This work was supported in part by the U.S. Naval Research Laboratory and in part by the National Polar-Orbiting Environmental Satellite System Integrated Program Office.

J. P. Bobak, D. J. Dowgiallo, and M. D. Anguelova are with the U.S. Naval Research Laboratory, Washington, DC 20375 USA (e-mail: justin.bobak@ nrl.navy.mil; david.dowgiallo@nrl.navy.mil; maggie.anguelova@nrl.navy.mil).

W. E. Asher is with the Applied Physics Laboratory, University of Washington, Seattle, WA 98105 USA (e-mail: asherwe@ apl.washington.edu).

Color versions of one or more of the figures in this paper are available online at http://ieeexplore.ieee.org.

Digital Object Identifier 10.1109/TGRS.2010.2103565 atmospheric marine boundary layer visibility, tropical cyclone intensification, and aerosol radiative forcing of climate (see summary and references in [1]). In addition, whitecaps affect microwave radiometric retrievals of ocean-surface wind vector [2], [3] and salinity [4], and visible wavelength retrieval of ocean color [5]. The importance of foam to air-sea interaction processes and ocean-surface electromagnetics indicates the need to measure and model these effects adequately in order to increase the accuracy of climate predictions and geophysical retrievals.

The effects of foam on physical processes are usually quantified in terms of foam fraction (whitecap coverage) $F_{c}$, defined as the fraction of the sea surface covered by visible foam generated by breaking waves, and a scaling parameter. In the case of electromagnetics, this scaling parameter is the emissivity of the foam-covered surface [6]. The conventional technique of measuring $F_{c}$ is through gray-scale analysis of photographs or video records of the sea surface [7], [8]. Using this method, numerous experimental campaigns have provided data for empirical parameterizations of $F_{c}$ as a function of wind speed (e.g., [1, Tables I and II]). However, water temperature, atmospheric stability, wave age, wave-current interaction, and wind history also influence $F_{c}$ [9], [10]. Developing a predictive relation for $F_{c}$ over the range of ocean conditions encountered globally requires that the dependence of $F_{c}$ on these additional factors be understood and quantified. The existing database of photographically measured $F_{c}$ represents only a limited range of conditions and does not suffice to quantify the geophysical variability of foam fraction. Thus, an algorithm estimating $F_{c}$ from satellite-measured brightness temperature $T_{B}$ of the ocean surface has been developed within the framework of the WindSat mission [11], [12].

The physical basis for estimating foam fraction from satellite microwave observations is the strong relationship between the presence of sea foam on the ocean surface and the ocean thermal emission $T_{B}\left(F_{c}\right)$ established by a long history of passive microwave measurements [3], [13]-[21]. The need to better quantify the geophysical variability of foam fraction has prompted continued efforts [1]. The method used in [1] has seen further development in [12], and this effort has resulted in the need to compare estimates of $F_{c}$ provided by satellite-measured brightness temperatures with directly measured in situ data to assess the performance of the algorithm. The Radiometry and Sea Surface Imagery (RASSI) experiment was designed to provide collocated and contemporaneous airborne photographic and radiometric, and WindSat radiometric data.

The RASSI data set can: 1) provide a basis to investigate the relation of photographically obtained $F_{c}$ values with $T_{B}$; 2) allow investigation of the effect of changes in local 


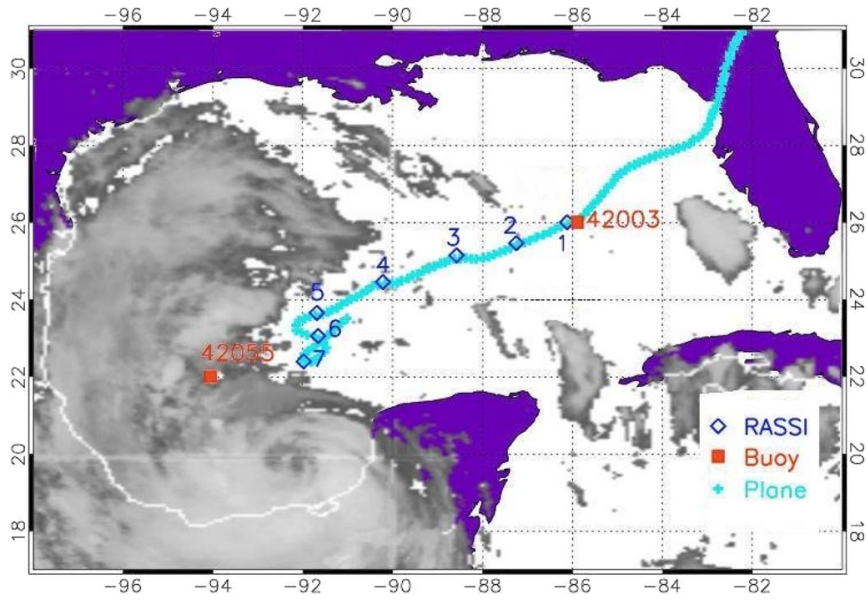

Fig. 1. RASSI flight over the Gulf of Mexico on August 21, 2007 (Crosses) Positions of aircraft track; (1)-(7) (diamonds) APMIR measuring stations; (squares) available NDCB buoys; and Hurricane Dean (overlaid infrared cloud image from the Geostationary Operational Environmental Satellite).

environmental conditions over regional scales on $F_{c}$; and 3) provide ground-truth data for assessing the performance of algorithms for retrieving foam coverage from satellitemeasured microwave brightness temperatures. This paper describes the RASSI experiment and the results from the first two activities listed earlier.

\section{EXPERIMENT AND DATA DESCRIPTION}

For the RASSI experiment, the Airborne Polarimetric Microwave Imaging Radiometer (APMIR) and a high-resolution high-altitude digital video camera system (FoamCam) were combined in the bomb bay of a U.S. Navy P3 research aircraft. This paper focuses on the data collected over the Gulf of Mexico.

\section{A. Gulf of Mexico Flight}

On August 21, 2007, Hurricane Dean was centered in the Bay of Campeche at the southern edge of the Gulf of Mexico. At this point, it was a Category 1 hurricane with maximum sustained winds on the order of $40 \mathrm{~m} \cdot \mathrm{s}^{-1}$ [22]. Fig. 1 shows the position of the storm (19.7 N, 92.2 W) at 23:45 UTC, August 21, 2007, and the RASSI flight path across the Gulf of Mexico.

During the flight, a pattern of three circles was performed at each of the seven stations (Fig. 1) as the aircraft followed a nearly radial approach to the storm center. The stations were chosen to be approximately evenly spaced along the flight line, with the added constraint that the circles be conducted in relatively cloud-free regions to allow FoamCam to image the ocean surface and to minimize the radiometric variability arising from spatially varying clouds. These circle patterns were approximately $3.5 \mathrm{~km}$ in radius, and each $360^{\circ}$ turn took $180 \mathrm{~s}$ at an average ground speed of $125 \mathrm{~m} \cdot \mathrm{s}^{-1}$. Table I lists the latitudes/longitudes of the center points and the times of the seven stations (shaded rows).

The flight altitude was $6600 \mathrm{~m}$ to support the characterization of the brightness temperature sensitivity to foam at larger spatial scales, to have the majority of the atmosphere below the aircraft (for easier comparison with brightness temperatures measured from space), and to give the radiometers a stable operating temperature.

\section{B. Radiometric Measurements}

A detailed description of APMIR can be found in [23]. During the RASSI experiment, vertically and horizontally polarized microwave brightness temperatures $T_{B}$ at 6.6, 6.8, and $7.2 \mathrm{GHz}$; vertically polarized microwave brightness temperature at $10.7 \mathrm{GHz}$; and fully polarimetric data at 19.35 and $37.0 \mathrm{GHz}$ (hereafter referred to as 19 and $37 \mathrm{GHz}$ ) were measured. The beamwidths of the 19- and 37-GHz horns are approximately $6^{\circ}$, giving footprints of $2.2 \times 1.3$ and $1.9 \times$ $1.1 \mathrm{~km}^{2}$ for the $19-$ and $37-\mathrm{GHz}$ radiometers, respectively. Data were taken at an incidence angle of $53^{\circ}$. During the flight on August 21, the full azimuthal dependence of $T_{B}$ was measured by having the aircraft circle each measuring station while APMIR was pointed perpendicularly to the flight direction.

On the ground, two external calibration targets, one immersed in liquid nitrogen and the other at ambient air temperature, provided end-to-end calibration. During flight, ambient and heated external calibration targets were viewed before and after each station.

\section{Video Measurements}

FoamCam consists of a monochrome camera with a resolution of 1392 by 1040 pixels and an $f 2.3$ zoom lens with a focal length range of 17-374 $\mathrm{mm}$. The nadir-viewing camera and lens were mounted in a custom housing approximately $2 \mathrm{~m}$ aft of APMIR. The camera was mounted so that the longer direction of its $4: 3$ aspect charge-coupled device array was aligned with the longitudinal axis of the aircraft. Images from the camera were digitized at frame rates from 1 to $3 \mathrm{~Hz}$. The electronic shutter speed and gain of the camera, as well as the focal length, focus, and aperture of the lens, were all controlled remotely. All images discussed here were taken with a focal length of $374 \mathrm{~mm}$, an $f$ number of 2.3 , and a shutter speed of $1 / 10000 \mathrm{~s}$.

Previous aircraft-based photographic measurements of $F_{c}$ have been conducted at altitudes ranging from $100 \mathrm{~m}$ [17]-[19] to several hundred meters [24]. Although the benefits in working at lower altitudes are obvious as far as the video is concerned, in order to study the sensitivity of brightness temperature to foam fraction at scales more appropriate for comparison with satellite instruments, higher altitudes are necessary. The main difficulty of high-altitude video imaging is that the contrast between the whitecaps and surrounding sea decreases exponentially with altitude due to light scattering from aerosols in the path between the aircraft and the ocean surface [25]. Although FoamCam was designed with the goal of minimizing this problem, the effect of the decrease in contrast on detecting whitecaps limited FoamCam to detecting only the actively breaking crests, which had the highest albedo.

The circular flight patterns used to collect the radiometric data also affected the sea-surface imagery because they increased both the distance from the camera to the water surface and the apparent ground speed of the sea surface in the camera image. The camera look direction was fixed with respect to the aircraft; thus, as the aircraft banked into the $30^{\circ}$ turn for the circle patterns, the slant range to the water surface for the 
TABLE I

Positions, Times, and Data for Surface Image Sets Collected During RASSi on August 21, 2007

\begin{tabular}{|l|l|l|l|l|l|l|l|}
\hline Image Set Number & $\begin{array}{l}\text { APMIR } \\
\text { Station } \\
\text { Number }\end{array}$ & $\begin{array}{l}\text { Latitude } \\
(\mathrm{deg})\end{array}$ & $\begin{array}{l}\text { Longitude } \\
(\mathrm{deg})\end{array}$ & $\begin{array}{l}\text { Time } \\
(\mathrm{UTC})\end{array}$ & $\begin{array}{l}\text { Number of } \\
\text { Images }\end{array}$ & $U_{10}\left(\mathrm{~ms}^{-1}\right)$ & $F_{c}$ \\
\hline 1 & & 26.11 & 86.02 & $20: 57$ & 556 & 10.28 & $3.38 \mathrm{E}-04$ \\
\hline 2 & & 25.98 & 86.08 & $20: 57$ & 56 & 10.46 & $6.55 \mathrm{E}-05$ \\
\hline 3 & 1 & 26.01 & 86.12 & $20: 57$ & 826 & 10.47 & $1.31 \mathrm{E}-04$ \\
\hline 4 & & 25.78 & 86.48 & NA & 288 & 10.16 & $9.19 \mathrm{E}-05$ \\
\hline 5 & & 25.67 & 86.70 & NA & 262 & 10.00 & $1.71 \mathrm{E}-04$ \\
\hline 6 & & 25.70 & 86.90 & NA & 374 & 10.00 & $1.07 \mathrm{E}-04$ \\
\hline 7 & 25.45 & 87.21 & $21: 18$ & 302 & 10.05 & $1.53 \mathrm{E}-04$ \\
\hline 8 & 25.47 & 87.25 & $21: 18$ & 538 & 10.06 & $7.51 \mathrm{E}-05$ \\
\hline 9 & & 25.46 & 87.24 & $21: 18$ & 118 & 10.06 & $4.74 \mathrm{E}-05$ \\
\hline 10 & & 25.24 & 87.60 & $21: 42$ & 870 & 10.39 & $1.46 \mathrm{E}-04$ \\
\hline 11 & 25.05 & 88.30 & $21: 42$ & 352 & 11.22 & $1.56 \mathrm{E}-04$ \\
\hline 12 & 25.15 & 88.58 & $21: 42$ & 532 & 11.28 & $2.60 \mathrm{E}-04$ \\
\hline 13 & 3 & 24.95 & 88.95 & $21: 42$ & 1102 & 12.04 & $9.98 \mathrm{E}-05$ \\
\hline 14 & & 24.70 & 89.45 & $21: 42$ & 386 & 13.20 & $1.42 \mathrm{E}-04$ \\
\hline 15 & & 24.59 & 89.66 & $22: 11$ & 100 & 13.67 & $2.30 \mathrm{E}-04$ \\
\hline 16 & 24.42 & 90.01 & $22: 11$ & 1008 & 13.49 & $2.70 \mathrm{E}-04$ \\
\hline 17 & & 24.46 & 90.22 & $22: 11$ & 718 & 13.11 & $7.97 \mathrm{E}-04$ \\
\hline 18 & & 24.41 & 90.36 & $22: 11$ & 778 & 13.03 & $2.21 \mathrm{E}-04$ \\
\hline 19 & & 23.59 & 91.59 & $22: 43$ & 362 & 13.69 & $2.06 \mathrm{E}-03$ \\
\hline 20 & & 23.66 & 91.69 & $22: 43$ & 1074 & 13.57 & $1.39 \mathrm{E}-03$ \\
\hline 21 & & 23.56 & 91.90 & $22: 43$ & 368 & 13.52 & $9.48 \mathrm{E}-04$ \\
\hline 22 & 23.07 & 91.59 & $23: 11$ & 566 & 14.75 & $1.40 \mathrm{E}-03$ \\
\hline 23 & & 23.06 & 91.66 & $23: 11$ & 834 & 14.74 & $2.22 \mathrm{E}-03$ \\
\hline 24 & 22.40 & 91.98 & $23: 38$ & 1952 & 15.96 & $1.97 \mathrm{E}-03$ \\
\hline
\end{tabular}

camera increased from $6600 \mathrm{~m}$ at nadir to $7600 \mathrm{~m}$. This changed the resolution of the camera and doubled the apparent velocity of the ocean surface in the video image.

Images were collected for each of the seven circle patterns flown during the August 21 RASSI flight. In addition, 17 image sets were collected while the aircraft was in level flight between the circle patterns. Table I lists the location and number of images collected for each image set.

\section{Additional Data}

The flight on August 21 was scheduled so that the P-3 would be on station in the Gulf of Mexico when WindSat was overhead. On that day, Special Sensor Microwave Imager/Sounder (SSMIS) F17, Special Sensor Microwave/Imager (SSM/I) F13 and F14, and QuickScat made overpasses of the region within a few hours. Table II gives the information for the satellite data used in this study, including their spatial resolutions, formats, and access. The F17 swath covered the entire Gulf of Mexico. F14 covered the western portion of the Gulf, while F13 covered the majority of the eastern section. Together, F14 and F13 give nearly full coverage of the Gulf; thus, their combined data are reported here for SSM/I. Since F17 provides data at each station, while F14 and F13 have to be combined, the SSMIS data are used in most comparisons hereinafter.

Standard meteorological and oceanographic data are available from National Data Buoy Center (NDBC, [26]) buoys 42003 and 42055 (Fig. 1) on 10-min and hourly bases.

The output from the Global Data Assimilation System (GDAS, National Centers for Environmental Prediction, [27]) numerical model was also used to provide $U_{10}, \varphi$, and $T_{s}$ (Table II) that could be spatially and temporally matched with the WindSat wind fields. Finally, a radiative transfer model pro- vided values for $T_{B}$ as a function of frequency and polarization for comparison with the brightness temperatures measured by APMIR.

\section{DATA PRocessing}

\section{A. APMIR Brightness Temperatures}

This analysis focuses on the 19- and 37-GHz vertically and horizontally polarized data (hereafter referred to as $19 \mathrm{~V}, 19 \mathrm{H}$, $37 \mathrm{~V}$, and $37 \mathrm{H}$ ), as these are the channels most affected by the presence of foam, and the data from corresponding channels are available from each of the satellite radiometers.

An error analysis looked at both calibration biases (error constant for at least the period of the August 21 flight) and calibration stabilities (errors not correlated through the whole flight). The analysis included various sources of radiometric error, such as quantization error, center frequency stability (thermally driven), detector linearity, biases in external calibration due to front-end reflections, radio frequency isolation, crosspolarization, sidelobe contamination, uncertainty in pointing, and radiometric noise (from NEDT and longer term gain stability). Two of these error sources dominated during the RASSI experiment: uncertainty in pointing and radiometric noise.

The data were corrected to a nominal Earth incidence angle (EIA) of 53.1 $1^{\circ}$ to match the SSM/I and SSMIS data. These sensors have the matching $19.35-\mathrm{GHz}$ channel and a common incidence angle at 19 and $37 \mathrm{GHz}$, whereas WindSat has incidence angles varying with frequency and a differing $18.7-\mathrm{GHz}$ center frequency [11]. It was necessary to estimate a pointing offset for the EIA correction because the typical procedure used to link aircraft attitude measurements to absolute antenna position measurements could not be accomplished. We estimated the 
TABLE II

Information on SOURCES For AND Formats of AVAILABle Data From VARious Satellite Sensors

\begin{tabular}{|c|c|c|c|c|c|}
\hline SOURCE & VARIABLES $^{1}$ & RESOLUTION & $\begin{array}{c}\text { FILE } \\
\text { FORMAT }\end{array}$ & DATA ACCESS & NOTES \\
\hline WindSat & $T_{B}, U_{10}, \varphi, T_{s}$ & Swath & Binary & NRL & $\begin{array}{c}\text { Orbit } 23945 \\
\text { Pixels at } 12.5 \mathrm{~km} \text { along \& } \\
\text { across track }\end{array}$ \\
\hline $\mathrm{SSM} / \mathrm{I}$ & $T_{B}$ & Swath & $\mathrm{HDF}^{2}$ & GHRC/MSFC $^{3}$ & Platforms F13 \& F14 \\
\hline SSMIS & $T_{B}$ & Swath & Binary & NRL & Platform F17 \\
\hline $\mathrm{SSM} / \mathrm{I}$ & $U_{10}$ & Grid $\left(0.25^{\circ} \times 0.25^{\circ}\right)$ & Binary & $\mathrm{RSS}^{4}$ & Platforms F13 \& F14 \\
\hline SeaWinds & $U_{10}, \varphi$ & Grid $\left(0.25^{\circ} \times 0.25^{\circ}\right)$ & Binary & $\mathrm{PODAAC} / \mathrm{JPL}^{5}$ & $\begin{array}{c}\text { Julian day } 234,1^{\text {st }} \text { descending } \\
\text { pass }\end{array}$ \\
\hline GDAS/NCEP $^{6}$ & $U_{10}, \varphi, T_{s}, T_{a}$ & Grid $\left(1^{\circ} \times 1^{\circ}\right)$ & GRIB $^{7}$ & CISL RDA $^{8}$ & The "final" 0-hour analysis \\
\hline
\end{tabular}

'Brightness temperature $\left(T_{B}\right)$, wind speed $\left(U_{10}\right)$, wind direction $(\varphi)$, sea surface temperature $\left(T_{s}\right)$, air temperature $\left(T_{a}\right)$.

${ }^{2} \mathrm{HDF}$ : Hierarchical Data Format.

${ }^{3}$ GHRC/MSFC: Global Hydrology Resource Center/ Marshal Space Flight Center, NASA (http://datapool.nsstc.nasa.gov/).

${ }^{4}$ RSS: Remote Sensing Systems (http://www.ssmi.com/).

${ }^{5}$ PODAAC/JPL: Physical Oceanography Distributed Active Archive Center at the NASA Jet Propulsion Laboratory (http://podaac.jpl.nasa.gov/).

${ }^{6}$ GDAS/NCEP: Global Data Assimilation Group, National Centers for Environmental Prediction (http://www.emc.ncep.noaa.gov/gmb/gdas/).

${ }^{7}$ GRIB: GRIdded Binary.

${ }^{8}$ CISL RDA: Research Data Archive at Computational and Information Systems Laboratory (http://dss.ucar.edu/datasets/ds083.2/).

TABLE III

CAlculated Errors and Variation in APMIR-Measured Brightness TemPerature

\begin{tabular}{|c|c|c|c|c|}
\hline Channel & $\begin{array}{c}\text { Error Analysis } \\
\text { Calibration Bias (K) }\end{array}$ & $\begin{array}{c}\text { Error Analysis Calibration } \\
\text { Stability (K) }\end{array}$ & $\begin{array}{c}\text { Actual Range of Brightness } \\
\text { Temperature Variation }{ }^{1}(\mathrm{~K})\end{array}$ & $\begin{array}{c}\text { Expected Uncertainty of } \\
\text { Brightness Temp }^{2}(\mathrm{~K})\end{array}$ \\
\hline $19 \mathrm{~V}$ & 3.3 & 1.5 & $1.3-6.4$ & $4.6-9.7$ \\
\hline $19 \mathrm{H}$ & 4.7 & 2.3 & $2.3-6.8$ & $7.0-11.5$ \\
\hline $37 \mathrm{~V}$ & 3.1 & 0.9 & $1.2-3.2$ & $4.3-6.3$ \\
\hline $37 \mathrm{H}$ & 3.9 & 0.7 & $1.4-6.9$ & $5.3-10.8$ \\
\hline
\end{tabular}

Includes actual calibration stability and natural variability.

${ }^{2}$ Obtained as the sum of calibration bias from error analysis (column 2) and actual variations of brightness temperature due to calibration stability and natural variability (column 4).

pointing offset from the elevation scans, usually performed for each flight, during which the radiometers were moved through nadir. From these scans, a pointing offset for each day was calculated. There was generally very good agreement from day to day between the estimated pointing offsets except for one outlier (from an earlier flight not discussed here). When this outlier is included, the pointing offset estimates have a standard deviation of 0.9 angular degrees, resulting in an uncertainty from $0.5 \mathrm{~K}$ to $1.8 \mathrm{~K}$ in brightness temperature for the channels studied here. This is counted as a bias for the day of August 21, as it would only change when the motion control system was powered off.

The radiometric noise of the APMIR measurements during the RASSI experiment, for reasons yet to be discovered, was particularly high. This was a problem for all four of the channels discussed here. Consequently, a significant potential calibration bias exists due to the noise during the calibration of the internal loads via the external loads. This potential bias was as large as $4.5 \mathrm{~K}$ for the $19 \mathrm{H}$ channel based on daily calibration of the internal loads from the external loads. The variation in the internal loads during data collection from the scene leads to a further calibration stability error of up to $2.3 \mathrm{~K}$ for this same channel. The various sources of calibration bias and stability estimated with this error analysis were combined and are presented in Table III (columns 2 and 3).

After calibration and correction, brightness temperatures were manually filtered to remove large variations due to uncorrected aircraft movements and other causes. Because video data do not show azimuthal variations, brightness temperatures were azimuthally averaged over all three circles flown at each station, and one $T_{B}$ value for each channel at each station is reported. The standard deviations of these brightness temperatures were, however, larger than the error-analysis estimates of the calibration stability (Table III, column 3). This is because, in addition to the calibration stability, the natural variability of the scene also contributes to the $T_{B}$ variations. These natural variations arise from such sources as cloud variability, azimuthal variation, and sidelobe contamination. Thus, the standard deviations of the brightness temperatures reported for each station quantify both the actual (not estimated) calibration stability and natural variability, as these are not easily separated. The resulting standard deviations varied significantly from station to station, so the range of the calculated values is listed in Table III (column 4).

The total expected uncertainty in the radiometric measurements is the combination of calibration bias, calibration stability, and natural variability. With the latter two combined, the total uncertainty is the sum of calibration bias and brightness temperature variability (Table III, column 5).

\section{B. FoamCam Whitecap Coverage}

Electronic noise in the video images was reduced by spatially filtering each image using a 2-D finite impulse response filter with an approximately circular 25-pixel width. The images were then analyzed for $F_{c}$ using the gray-scale analysis procedures described in [7] and [8] with brightness thresholds selected using the method described in [28]. Fig. 2(a) shows 


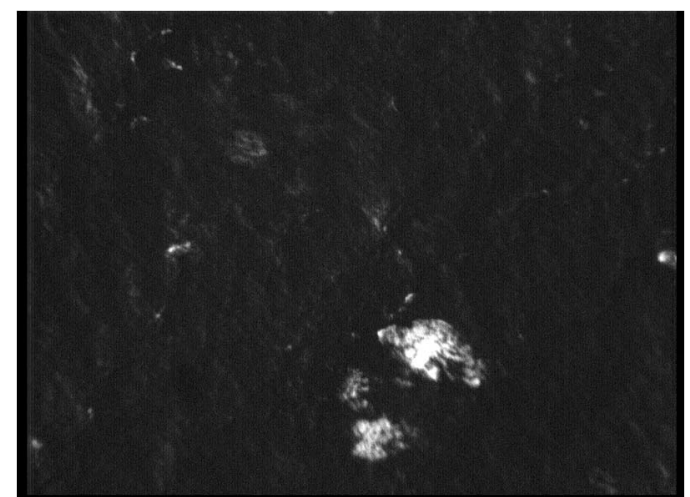

(a)

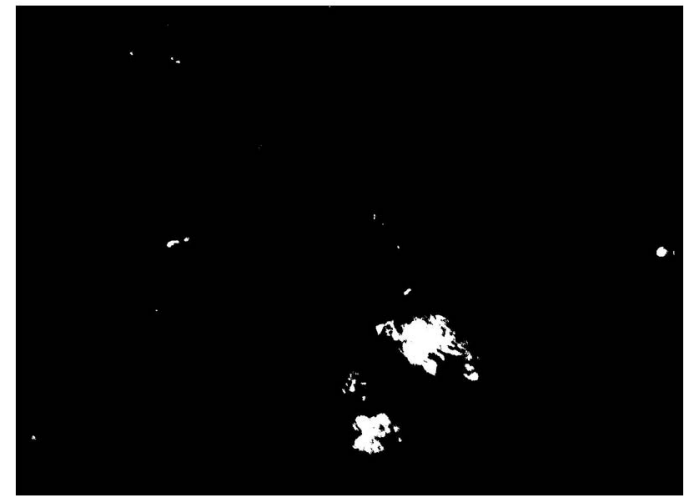

(b)

Fig. 2. Typical sea-surface image taken with $f . l .=374 \mathrm{~mm}, f 2.3$, and a shutter speed of $1 / 10000 \mathrm{~s}$ and (b) its corresponding segmented image used to calculate $F_{c}$. This image was taken at station 6 (see Table I).

a sea-surface image taken from an altitude of $6618 \mathrm{~m}$ at station 6 (Table I). Fig. 2(b) shows the segmented version of Fig. 2(a), with areas detected to be actively breaking wave crests in white.

Because the presence of clouds at altitudes below $6600 \mathrm{~m}$ or sun glint on the surface can bias the resulting average $F_{c}$ value, cloud/glint-contaminated images must be removed. Images contaminated by the presence of clouds or by sun glint were identified and removed using a two-step filtering procedure.

In the first filtering step, the criterion used to remove images containing clouds and glint is to determine the largest realistic total foam coverage $F_{c \mathrm{MAX}}$, which might occur only through whitecaps. Our estimate of $F_{c \mathrm{MAX}}$ is based on the whitecap spatial characteristics. Because the physical scale of the largest breaking waves at wind speeds comparable to these during the RASSI experiment (e.g., $16 \mathrm{~m} \mathrm{~s}^{-1}$ ) is on the order of $5 \mathrm{~m} \mathrm{[29],}$ a single breaking wave in an image such as shown in Fig. 2(a) results in an $F_{c}$ of 0.0044 . Assuming that there would be, at most, five such waves in any particular image [30], we obtain $F_{c \text { MAX }} \approx 0.022$. Therefore, the initial filter removes images where $F_{c}$ is greater than 0.2 or an order of magnitude larger than $F_{c \text { MAX. }}$.

The second filtering step is to recognize that, due to spatial scales larger than those of whitecaps, clouds and glint in general persist from image to image over many frames. Therefore, the presence of clouds or glint could also be identified by finding sequences of images where the $F_{c}$ for each image is greater than the average $F_{c}$ plus twice the standard deviation of $F_{c}, \sigma_{F}$, for that set of images. Fig. 3 shows a plot of $F_{c}$ for each image in

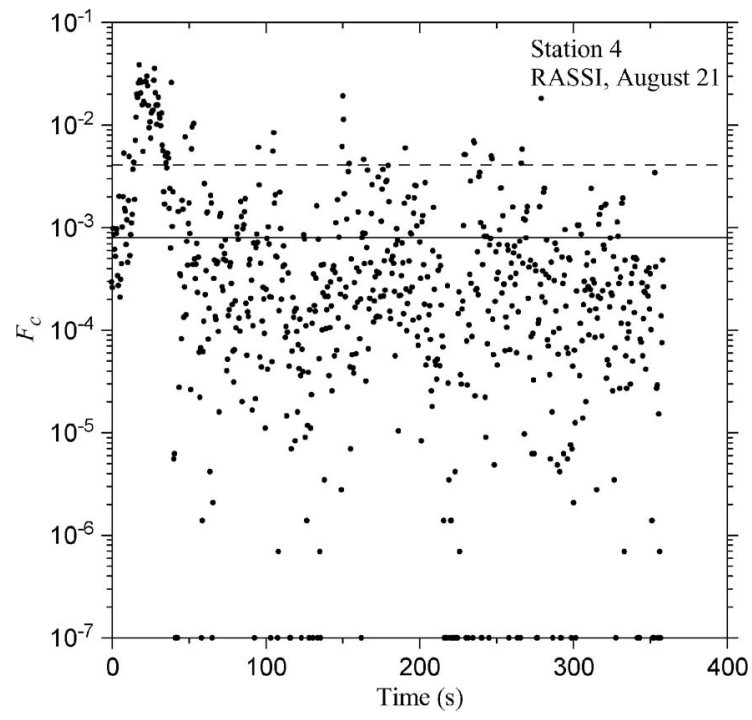

Fig. 3. Time series of foam fraction $F_{c}$ for the sea-surface video images taken at station 4 .

the set of images recorded at station 4 . The solid horizontal line shows the average $F_{c}$, and the dashed line shows $F_{c}+2 \sigma_{F}$. The presence of clouds is seen as the increase in $F_{c}$ for the times 10 to $40 \mathrm{~s}$.

These two filtering steps typically left 30 to 40 images per set with values for $F_{c}$ greater than $F_{c}+2 \sigma_{F}$, and to ensure that these are cloud-free images, they were examined manually. As a check on the algorithm mistakenly identifying cloud-free images as containing clouds, a random sample of 600 of the 6000 images identified as containing clouds and glint were checked manually to make sure that they are cloud contaminated.

\section{Comparing Data From Different Sources}

On August 21, the WindSat pass over the Gulf of Mexico at 23:26 UTC was closely matched in time for stations 7, 6, and 5 , with time differences $\Delta t$ of $-12,+15$, and $+43 \mathrm{~min}$, respectively, and reaching $+150 \mathrm{~min}$ for station 1 . For the $\mathrm{SSM} / \mathrm{I}$ data, the $\Delta t$ values follow those of WindSat closely (Fig. 4(a), open squares). There was less synchronization with QuickSCAT, where $\Delta t=+67 \mathrm{~min}$ at station 7 . The closest match for GDAS data is from 00 UTC on August 22, which results in $\Delta t=+22$ min at station 7 .

Because of the temporal and spatial offsets (Fig. 4) and differences in spatial resolution between the different RASSI data sets (Table II), the approach described in [31] was used for comparing the satellite, aircraft, and in situ data. Brightness temperatures measured by APMIR were spatially and temporally averaged over the entire circle pattern made at each measuring station (Section III-A). The average values of $F_{c}$ at each station were calculated using at least $500 \mathrm{cloud} / \mathrm{glint}$-free images from each circle pattern (Table I). Typically, this covered at least $40 \%$ of the total time spent in the circle pattern. We average the available satellite-measured brightness temperatures for each RASSI station using the number of points falling within a $0.5^{\circ} \times 0.5^{\circ}$ box (approximately $55 \times 55 \mathrm{~km}$ at the latitude of the Gulf of Mexico). Depending on the swath 

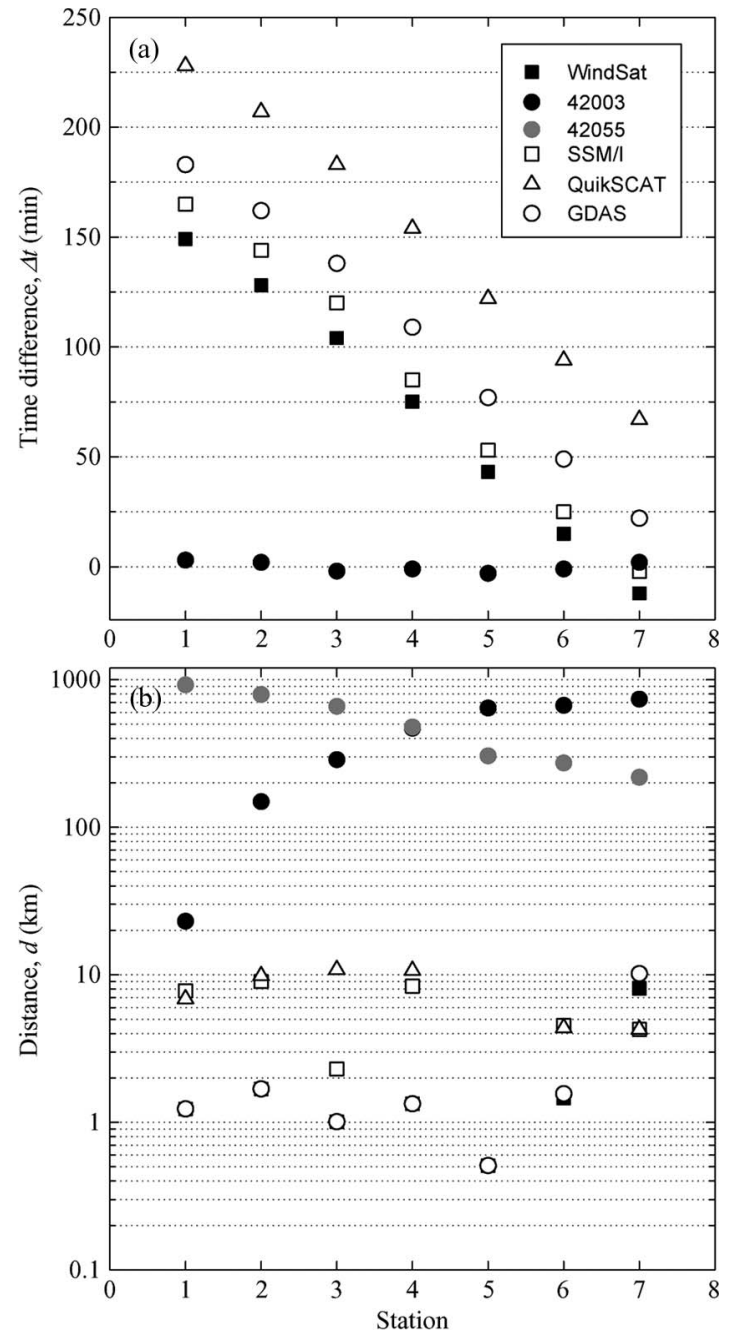

Fig. 4. (Panel a) Time difference $\Delta t$, and (panel b) distance $d$ between RASSI stations and various sources of brightness temperature $T_{B}$ (in kelvins) and wind speed $U_{10}$ (in meters per second) values. Note that, in panel a, the data for the two buoys (black and gray solid circles) coincide in time.

resolutions (Table II), the number of points used to obtain averaged $T_{B}$ values ranged from 5 to 42 .

For $U_{10}$ and other gridded data (Table II), we performed similar spatial averaging after interpolation to or resampling around each RASSI station. The in situ data from the NDBC buoys were temporally averaged over time periods of $1 \mathrm{hr}$ and $30 \mathrm{~min}$ for \#42003 and $1 \mathrm{hr}$ for \#42055. A comparison of the standard deviations of $U_{10}, d$, and $\Delta t$ for each considered data set identifies the temporal and spatial offsets for the WindSat as the smallest. We thus work with the WindSat values for $U_{10}$.

\section{RESUlts AND Discussion}

During the RASSI measurements while Hurricane Dean was approaching, $U_{10}$ ranged from a minimum of $10 \mathrm{~m} \cdot \mathrm{s}^{-1}$ at station 2 to $16 \mathrm{~m} \cdot \mathrm{s}^{-1}$ at station 7 (Table I). The air-sea temperature differences $\Delta T$ (defined as $T_{a}-T_{s}$ ) recorded by the buoys show that the atmospheric stratification in the entire region is unstable with $\Delta T=-0.6{ }^{\circ} \mathrm{C}$ at buoy 42003 and
$\Delta T=-0.4{ }^{\circ} \mathrm{C}$ at buoy $\# 42055$. The significant wave height ranged from 2 to $3 \mathrm{~m}$.

\section{A. Brightness Temperature}

For the RASSI observational conditions, Fig. 5 shows the plots of $T_{B}$ for $19 \mathrm{~V}$ and $19 \mathrm{H}$ (panels a and b) and $37 \mathrm{~V}$ and $37 \mathrm{H}$ (panels $\mathrm{c}$ and d) measured by (black squares) APMIR, (open squares) WindSat, (circles) SSMIS, and (triangles) SSM/I versus radial distance to the eye of Hurricane Dean. The error bars on APMIR data represent the sum of the calibration bias and the range of scene variation for each particular station (column 5 in Table III; see discussion in Section III-A).

The correlation between the $19 \mathrm{~V}$ brightness temperatures from APMIR and those from SSMIS is 0.80, while the $19 \mathrm{H}$ data are over $91 \%$ correlated. The average bias at $19 \mathrm{H}$ is $-3.1 \mathrm{~K}$, which is well within the expected calibration bias (see Table III), although at $19 \mathrm{~V}$, the average bias is $-4.5 \mathrm{~K}$, which is about $1.2 \mathrm{~K}$ higher than what would be expected. However, as can be seen in Fig. 5, the APMIR data agree with most of the satellite data to within the expected error (bias plus scene variation). The results are summarized in Table IV. Table IV also lists the comparisons between APMIR and the two SSM/I sensors (F13 and F14) that were overhead during the flight.

The correlations of APMIR $37 \mathrm{~V}$ brightness temperatures with those of WindSat and SSMIS are 0.87 and 0.90, respectively, while for $37 \mathrm{H}$, the correlations are 0.96 with each sensor. The vertical channel bias against SSMIS is less than $0.5 \mathrm{~K}$ and is about $-2.6 \mathrm{~K}$ when compared to WindSat. This is within the expected bias of $3.1 \mathrm{~K}$. The horizontal channel has biases of $-5.8 \mathrm{~K}$ and $-4.8 \mathrm{~K}$ (Table IV), which are larger than the expected value of $3.9 \mathrm{~K}$ (Table III), but radiative transfer modeling suggests that there could easily be $1 \mathrm{~K}$ of brightness temperature change (H-polarization) from the atmosphere above the aircraft.

To obtain a measure of the variation that can be expected based on different viewing geometries and measurement times, Table IV includes a comparison of $37 \mathrm{GHz}$ data between WindSat and SSMIS. The WindSat $37 \mathrm{~V}$ brightness temperatures are an average of $3.1 \mathrm{~K}$ higher than those for SSMIS, with a $0.8 \mathrm{~K}$ standard deviation. For $37 \mathrm{H}$, the bias is $1.0 \mathrm{~K}$, with a $1.2 \mathrm{~K}$ standard deviation. Examining the values in Table IV, for $37 \mathrm{~V}$, APMIR data agree with the data from the two satellites, as well as the brightness temperatures from the satellites agree with each other. On the other hand, at $37 \mathrm{H}$, APMIR has a significant bias compared to the intersatellite number (some of this bias is due to atmosphere above the aircraft), but the APMIR data still have a very good correlation with the data from satellites.

Overall, the oceanic brightness temperatures measured by APMIR can be corrected and used as surrogates for values that would be measured by WindSat under the same conditions. APMIR data can thus be used to develop, test, and evaluate algorithms for retrieving foam fraction from radiometric observations.

\section{B. Foam Fraction}

Table I lists the values of $F_{c}$ and $U_{10}$ for each image set collected on the August 21 flight. These data are shown in 

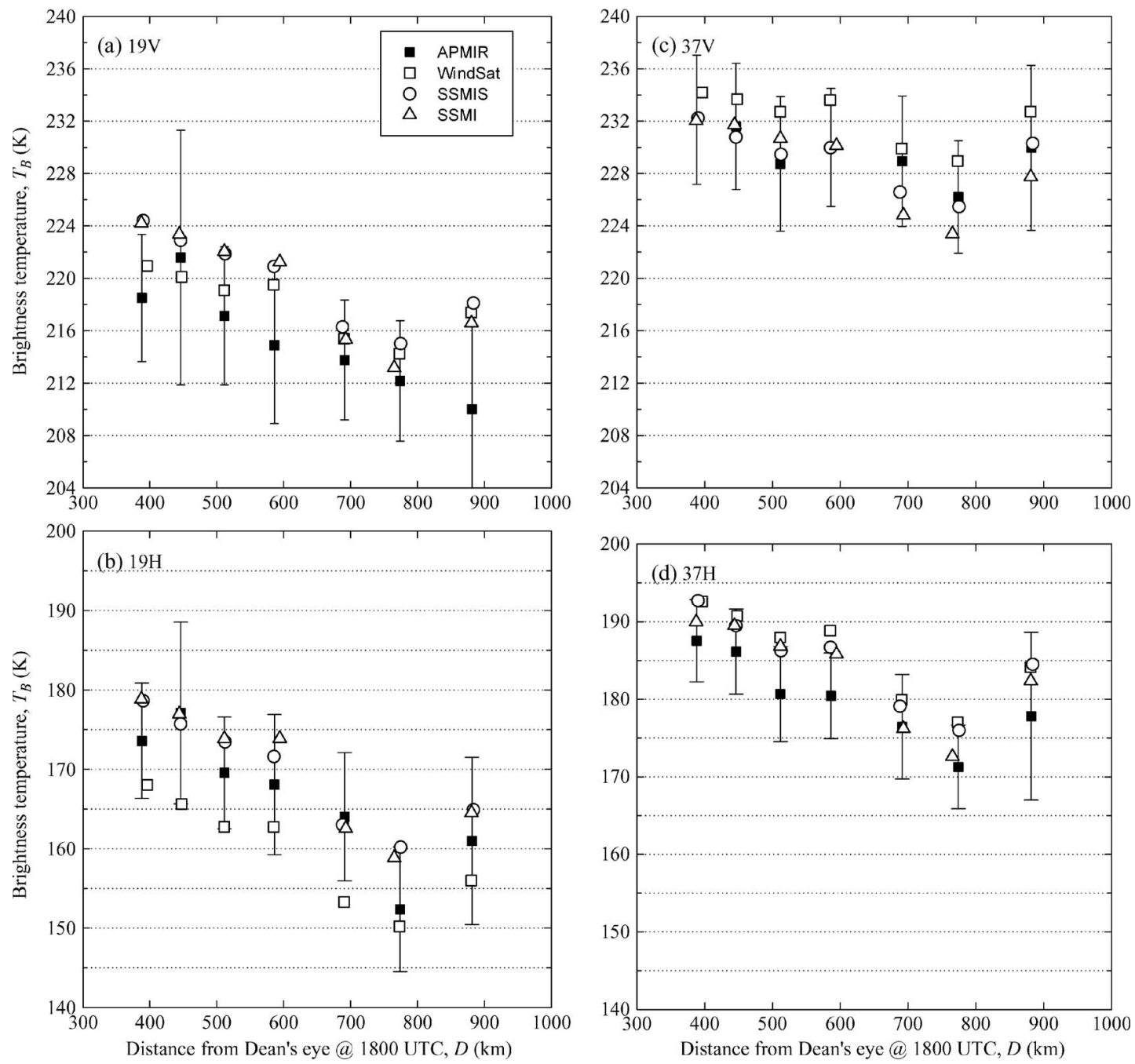

Fig. 5. Brightness temperature $T_{B}$ (in kelvins) measured on August 21, 2007, at each station from various sources.

Fig. 6, along with the parameterizations of the form $F_{c}=$ $A\left(U_{10}-B\right)^{3}$ obtained using least squares linear regression of $F_{c}^{1 / 3}$ with $U_{10}$, as suggested in [32], from five previous measurements of whitecap coverage made using video cameras mounted on ships [7], [8], [28], [32], [33]. The RASSI $F_{c}$ data have approximately the same dependence on $U_{10}$ and similar scatter in the individual values of $F_{c}$ at a given $U_{10}$ as the shipbased measurements but are, on average, a factor of eight lower at a given $U_{10}$. This difference can be explained in terms of the performance of the camera/lens system coupled with the relatively high altitude at which these measurements were made.

The modulation transfer function (MTF) of a lens defines its ability to resolve differences in contrast [34]. It is known that the MTF decreases as the aperture size increases, and the decrease in MTF implies a decrease in the ability of the lens to resolve differences in contrast [34]. Contrast resolution of lens is important in measuring $F_{c}$ because the total foam coverage is the sum of the area of the actively breaking waves (stage-A whitecaps) and the area of the decaying bubble plumes and foam (stage-B whitecaps) left in the wakes of the stageA whitecaps. These two stages have different video signatures in terms of brightness threshold, with the decaying plumes being less bright than the actively breaking wave crests [32].
Furthermore, the spatial coverage of these bubble plumes is a factor of eight larger than the actively breaking crests [32]. Given the low contrast inherent in sea-surface images taken from high altitudes (Section II-C), the ability of the camera to resolve differences in contrast is critical in interpreting the foam coverage data.

Fig. 2(a) shows an image of the sea surface taken at APMIR station 6 using a focal length of $374 \mathrm{~mm}$, a shutter speed of 1/10000 s, and an $f$ number of 2.3. Fig. 2(b) shows the corresponding segmented image and the area detected to be breaking waves and bubble plumes using a brightness threshold of 0.36 (with $F_{c}=0.0031$ for this image), which is the minimum that can be used and still separate pixels that are clearly unbroken sea surface from pixels that are the crests of breaking waves. However, a threshold of 0.36 is too high to detect all the light gray patches in the image that are decaying bubble plumes left behind by breaking waves. This means that it is impossible to separate foam from unbroken sea surface using these camera parameters. Therefore, the most likely explanation for why the $F_{c}$ values are a factor of eight lower than previous measurements is that the low contrast in the images caused by working at high altitudes, combined with the low MTF due to the large aperture of the lens, prevented thin foam layers and 
TABLE IV

Statistics of Data COMParisons, APMIR Versus WindSAT, SSMIS, ANd SSM/I FOR All Frequency/Polarization ChanNELS

\begin{tabular}{|c|c|c|c|c|}
\hline Sensor/channel 1 & Sensor/channel 2 & Correlation & $\begin{array}{c}\text { Bias } \\
\text { (channel 1 channel 2) (K) }\end{array}$ & $\begin{array}{c}\text { Standard deviation of (channel } \\
1-\text { channel 2) (K) }\end{array}$ \\
\hline APMIR 19V & WindSat 18V & 0.73 & -2.7 & 2.7 \\
\hline APMIR 19H & WindSat 18H & 0.92 & 6.7 & 3.3 \\
\hline APMIR 19V & SSMIS 19V & 0.80 & -4.5 & 2.4 \\
\hline APMIR 19H & SSMIS 19H & 0.92 & -3.1 & 3.4 \\
\hline APMIR 19V & SSM/I F13 19V* & & -2.8 & 3.1 \\
\hline APMIR 19H & SSM/I F13 19H* & & -4.7 & 2.0 \\
\hline APMIR 19V & SSM/I F14 19V* & & -3.8 & 2.7 \\
\hline APMIR 19H & SSM/I F14 19H* & & -2.6 & 1.0 \\
\hline APMIR 37V & WindSat 37V & 0.87 & -5.8 & 1.7 \\
\hline APMIR 37H & WindSat 37H & 0.96 & 0.5 & 1.1 \\
\hline APMIR 37V & SSMIS 37V & 0.90 & -4.8 & 1.5 \\
\hline APMIR 37H & SSMIS 37H & 0.96 & 3.1 & 1.0 \\
\hline APMIR 37V & SSM/I F13 37V* & & -1.9 & 0.9 \\
\hline APMIR 37H & SSM/I F13 37H* & & -0.5 & 0.9 \\
\hline APMIR 37V & SSM/I F14 37V* & & -4.3 & 1.7 \\
\hline APMIR 37H & SSM/I F14 37H* & & 3.1 & 1.0 \\
\hline WindSat 37V & SSMIS 37V & 0.96 & 0.98 & \\
\hline WindSat 37H & SSMIS 37H & & & 1.2 \\
\hline
\end{tabular}

*Comparison is based on only 3 stations for F13 and 4 stations for F14, so correlations are not calculated.

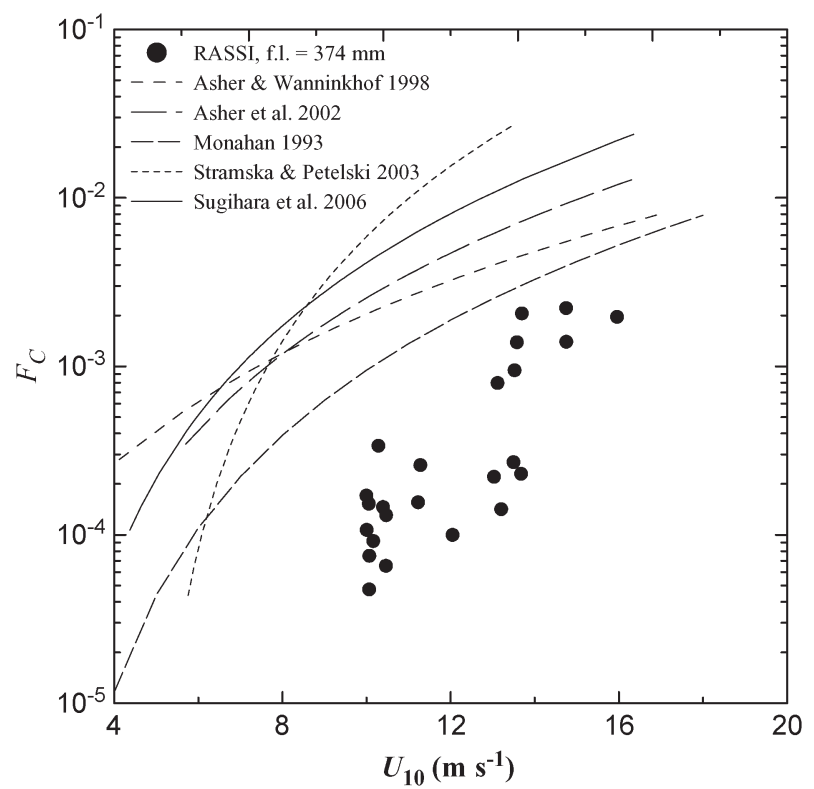

Fig. 6. Foam fraction $F_{c}$ as a function of wind speed $U_{10}$ (in meters per second) for RASSI video data collected on August 21. Also shown in the figure are parameterized results from five previous ship-based experiments that measured $F_{c}$ [7], [8], [28], [32], [33].

bubble plumes (i.e., stage-B whitecaps) from being included in the foam coverage.

While sea-surface emissivity is a function of both the stage-A and stage-B whitecap coverages, radiometric data do not allow clear separation of the emissivity of active whitecaps from that of the decaying whitecaps [18]. Thus, it would have been advantageous to measure both active and decaying whitecaps during RASSI with FoamCam. Because the RASSI $F_{c}$ values are only of the active whitecaps, a correction is required when comparing $F_{c}$ values from RASSI with the results from other observations of whitecaps. Such a correction can be developed from previous data sets for foam fraction because the stage-B coverage scales with the stage-A coverage [32].

The merit of the collected $F_{c}$ data, however, is that it provides stage-A whitecap coverage, and the combination of these $F_{c}$ values with the radiometric data enables direct correlation of concurrent and collocated data for $F_{c}$ and $T_{B}$. Furthermore, being associated with actively breaking waves, stage-A whitecaps are needed to quantify dynamical processes such as transfer of momentum, energy dissipation, turbulent mixing, gas exchange, spume droplet production (apart from bubble-mediated production), and generation of ambient noise.

\section{Microwave Thermal Emission in Presence of Whitecaps}

Fig. 7 shows the $T_{B}$ at $18-19 \mathrm{GHz}(\mathrm{V}$ and $\mathrm{H}$ polarizations; panels $\mathrm{a}$ and $\mathrm{b}$ ) and $37 \mathrm{GHz}(\mathrm{V}$ and $\mathrm{H}$ pol, panels $\mathrm{c}$ and $\mathrm{d}$ ) for both WindSat and APMIR, plotted as a function of $F_{c}$ from FoamCam. The sensitivity of brightness temperature at $\mathrm{V}$ and $\mathrm{H}$ polarizations to changes in foam fraction $\Sigma_{V}$ and $\Sigma_{H}$, respectively, for each sensor and frequency was calculated by performing a least squares linear regression on the data in Fig. 7 with the results given in Table $\mathrm{V}$ (in units of kelvin per percent $F_{c}$ ). Table $\mathrm{V}$ also provides the ratio of $\Sigma_{H}$ to $\Sigma_{V}$ at each frequency for each sensor.

As can be seen in Table $\mathrm{V}$, the ratios of $\Sigma_{H}$ to $\Sigma_{V}$ at $18 \mathrm{GHz}$ for WindSat and at $37 \mathrm{GHz}$ for APMIR, SSMIS, and WindSat 

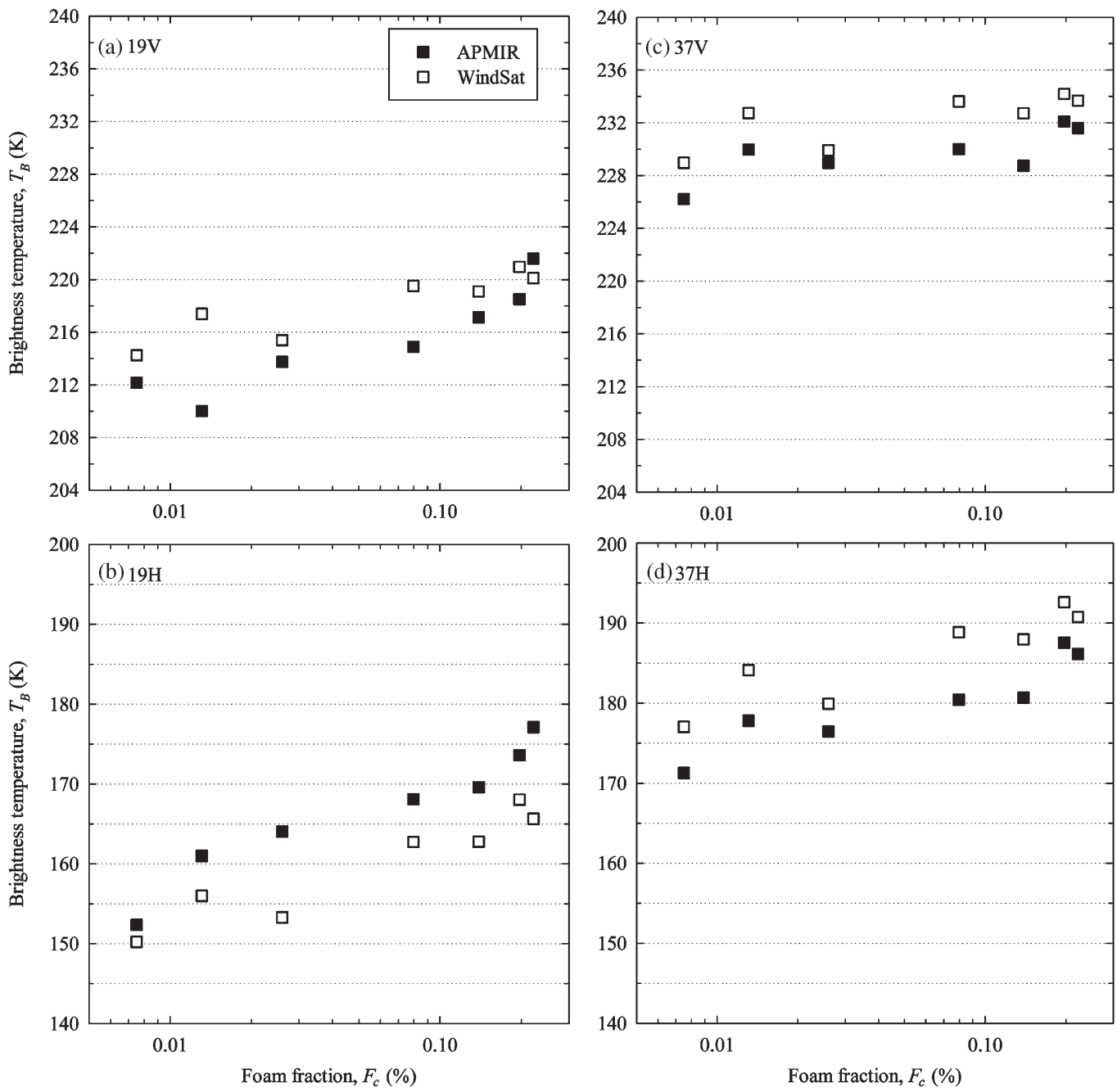

Fig. 7. APMIR and WindSat brightness temperatures $T_{B}$ (in kelvins) as a function of foam fraction $F_{c}$.

TABLE V

SENSITIVITy OF BRightness TEMPERATURE MEASURED With APMIR, WINDSAT, AND SSMIS TO FOAM FRACTION FOR ALL FREQUENCY/POLARIZATION CHANNELS

\begin{tabular}{|c|c|c|c|}
\hline $\begin{array}{c}\text { Sensor/Frequency } \\
(\mathrm{GHz})\end{array}$ & $\begin{array}{c}\text { V-pol sensitivity } \\
\Sigma_{V}\left(\mathrm{~K} / F_{C}(\boldsymbol{\%})\right)\end{array}$ & $\begin{array}{c}\text { H-pol sensitivity } \\
\Sigma_{H}\left(\mathrm{~K} / F_{C}(\mathbf{\%})\right)\end{array}$ & $\frac{\Sigma_{H}}{\Sigma_{V}}$ \\
\hline APMIR/19 & 42 & 84 & 2.0 \\
\hline SSMIS/19 & 36 & 73 & 2.0 \\
\hline WindSat/18 & 24 & 68 & 2.8 \\
\hline APMIR/37 & 16 & 58 & 3.6 \\
\hline SSMIS/37 & 20 & 56 & 2.8 \\
\hline WindSat/37 & 16 & 56 & 3.4 \\
\hline
\end{tabular}

are all 2.8 or larger with a ratio of $\Sigma_{H}$ to $\Sigma_{V}$ at $19 \mathrm{GHz}$ for APMIR and SSMIS equal to 2.0. Previous estimates by Smith [19] found the ratio of $\Sigma_{H}$ to $\Sigma_{V}$ at $37 \mathrm{GHz}$ to be 1.9, which is somewhat lower than the one measured here. However, the data reported in [19] were collected at a wind speed of $10 \mathrm{~m} / \mathrm{s}$ for large waves breaking on a shoal. Therefore, it is possible that the differences of ocean-surface roughness from small-scale waves, which also contribute to the difference in ocean-surface emissivity between vertical and horizontal polarizations, are responsible for the increased values of the $\Sigma_{H}-$ to- $\Sigma_{V}$ ratios measured during RASSI.

Webster et al. [18] reported $\Sigma_{H}$ values on the order of $0.08 \mathrm{~K} / F_{c}(\%)$ at $19 \mathrm{GHz}$, which are considerably lower than the $\Sigma_{H}$ values listed in Table V. One difference is that Webster et al. [18] report $\Sigma_{H}$ in terms of "white water" coverage, not whitecap fraction. Given that Webster et al. [18] do not specifically define how they estimate white water coverage from their photographic images, they also report that the whitecap coverage during their measurements was relatively constant at $4 \%$ (with the increase in white water coverage due to foam and foam streaks). In addition, the measurements in [18] were made under fetch-limited conditions, and roughness effects on emissivity may also contribute to the observed $\Sigma_{H}$.

Intercomparing only the RASSI data, Fig. 7 shows that the changes in brightness temperature $\Delta T_{B}$ are smaller for WindSat than those for APMIR, implying a decrease in sensitivity of the average scene brightness temperature to foam on the surface. This decrease in sensitivity is larger for $18-19 \mathrm{GHz}$ than for $37 \mathrm{GHz}$, with $\Delta T_{B}$ values for $\mathrm{H}$ polarization at $18-19 \mathrm{GHz}$ for APMIR and WindSat being $25 \mathrm{~K}$ and $18 \mathrm{~K}$, respectively. In contrast, at $37 \mathrm{GHz}$, for $\mathrm{H}$ polarization, the $\Delta T_{B}$ values for APMIR and WindSat are similar at $15.8 \mathrm{~K}$ 
and $15.6 \mathrm{~K}$, respectively. This suggests that the atmosphere has a stronger effect on the satellite-based measurements at 18-19 GHz than at $37 \mathrm{GHz}$. While larger $\Delta T_{B}$ for $\mathrm{H}$ polarization at $18-19 \mathrm{GHz}$ supports the conclusion in [1] in that this frequency is suitable for sea-state measurements, including the appearance of foam, the findings here imply that the estimates of $F_{c}$ at $18-19 \mathrm{GHz}$ might require more accurate atmospheric corrections than the estimates made at higher frequency. It would be wise, therefore, to consider the use of $37 \mathrm{GHz}$ for obtaining satellite-based estimates of $F_{c}$ in addition to data at $18-19 \mathrm{GHz}$.

\section{Summary And CONCLUSion}

We have presented airborne observations of the dependence of both microwave brightness temperature and whitecap coverage on wind speed over spatial scales that are similar to those measured by satellite-mounted radiometers. Previous airborne measurements made at low [19] and high [17], [24] altitudes either have lacked concurrent/collocated measurements of microwave brightness temperature and whitecap coverage or have brightness temperature measurements over a more limited range of wind speeds. Previous airborne measurements of both brightness temperature and whitecap coverage were made from aircraft flying at low altitude [17], [18]. Although these previous measurements have been invaluable in understanding the response of brightness temperature to changes in wind speed, until now, there has been a gap in observational results quantifying the response of satellite-based brightness temperatures measured at spatial scales of hundreds of square kilometers to changes in scene-averaged foam coverage caused by breaking waves with individual spatial scales that are much smaller than the spatial scale of the measurement.

The data measured during the RASSI experiment have shown that the sensitivity of brightness temperature to changes in coverage of wave breaking over larger spatial scales is consistent with the predictions made from measurements at much smaller spatial scales. This furthers the understanding of how to compare foam fraction data obtained from in situ photographic measurements to those estimated from satellite radiometric observations. Such comparisons are critical for constraining satellite-based foam fraction estimates that are required to properly account for the effects of breaking waves on global biogeochemical processes.

The sensitivity of brightness temperatures measured by APMIR, WindSat, and SSMIS with respect to changes in wind speed and foam coverage is in qualitative agreement with past experiments made at lower altitudes in that the dependence of brightness temperature measured for horizontal polarization on both wind speed and foam coverage was found to be much stronger than the dependence measured for vertical polarization. However, the sensitivities found in this experiment were significantly larger than those found by previous researchers working at lower altitudes. Complete interpretation of the RASSI data presented here to explain this difference is beyond the scope of this paper but will be examined in future work. The roles of atmospheric effects (related to using brightness temperatures measured at high altitude), differences in lateral spatial scales between these data and previous measurements, and differences in the wave field caused by fetch, water depth, or wind-current interactions between these and previous measurements will be examined by further analysis of this data set.

This experiment demonstrated that the APMIR data have sufficiently high correlation with the satellite data to aid in developing algorithms for retrieving foam coverage from WindSat and similar microwave radiometers. The second key result was the demonstration of the ability to measure the areal coverage of actively breaking waves from an altitude of over $6 \mathrm{~km}$. When coupled with the agreement between the APMIR, WindSat, SSMIS, and SSM/I brightness temperatures, the foam coverages provide the first data set that can be used as ground truth for foam-retrieval algorithms. The results also suggest that the future experiments should use a higher resolution camera on a gimbal mount to minimize the slant length to the water surface to improve scene contrast. Furthermore, the results have shown that identifying and correcting sources of noise in the radiometric measurements are critical.

\section{ACKNOWLEDGMENT}

The authors would like to thank the Navy Scientific Development Squadron One (VXS-1) for the operational support with respect to the planning and execution of the flight on August 21, 2007, N. R. McGlothlin, Jr. (Praxis, Inc.) and T. E. vonRentzell (formerly with Interferometrics, Inc.) for their engineering and technical support during the RASSI flights, and G. Poe (Naval Research Laboratory, Monterey, CA), A. Uliana, T. vonRentzell, B. Gardiner (all formerly with Interferometrics, Inc.), B. Thomas (Aerospace Corporation, Omaha, Nebraska), and J. Tesmer (Fleet Numerical Meteorology and Oceanography Center, Monterey) for providing the F-17 SSMIS, F-16 SSMIS and SSM/I data products.

\section{REFERENCES}

[1] M. D. Anguelova and F. Webster, "Whitecap coverage from satellite measurements: A first step toward modeling the variability of oceanic whitecaps," J. Geophys. Res., vol. 111, pp. C03017-1-C03017-23, Mar. 2006.

[2] S. H. Yueh, W. J. Wilson, S. J. Dinardo, and F. K. Li, "Polarimetric microwave brightness signatures of ocean wind directions," IEEE Trans. Geosci. Remote Sens., vol. 37, no. 2, pp. 949-959, Mar. 1999.

[3] S. Padmanabhan, S. C. Reising, W. E. Asher, L. A. Rose, and P. W. Gaiser, "Effects of foam on ocean surface microwave emission inferred from radiometric observations of reproducible breaking waves," IEEE Trans. Geosci. Remote Sens., vol. 44, no. 3, pp. 569-583, Mar. 2006.

[4] A. Camps, M. Vall-llossera, R. Villarino, M. Reul, B. Chapron, I. Corbella, N. Duffo, F. Torres, J. J. Miranda, R. Sabia, A. Monerris, and R. Rodriguez, "The emissivity of foam-covered water surface at L-band: Theoretical modeling and experimental results from the FROG 2003 field experiment," IEEE Trans. Geosci. Remote Sens., vol. 43, no. 5, pp. 925937, May 2005.

[5] H. R. Gordon and M. Wang, "Influence of oceanic whitecaps on atmospheric correction of ocean-color sensors," Appl. Opt., vol. 33, no. 33, pp. 7754-7763, Nov. 1994.

[6] A. Stogryn, "The emissivity of sea foam at microwave frequencies," J. Geophys. Res., vol. 77, no. 9, pp. 1658-1666, Mar. 1972.

[7] W. E. Asher and R. Wanninkhof, "The effect of bubble-mediated gas transfer on purposeful dual gaseous-tracer experiments," J. Geophys. Res., vol. 103, no. C5, pp. 10555-10 560, May 1998.

[8] W. E. Asher, J. B. Edson, W. R. McGillis, R. Wanninkhof, D. T. Ho, and T. Litchendorf, "Fractional area whitecap coverage and air-sea gas transfer velocities measured during GasEx-98," in Gas Transfer at Water Surfaces, vol. 127, Geophysical Monograph, M. A. Donelan, W. M. Drennan, E. S. Saltzman, and R. Wanninkhof, Eds. Washington, DC: AGU, 2002, pp. 199-204. 
[9] G. F. Williams, Jr., "Microwave radiometry of the ocean and the possibility of marine wind velocity determination from satellite observations," J. Geophys. Res., vol. 74, no. 18, pp. 4591-4594, Aug. 1969.

[10] E. C. Monahan and I. G. O'Muircheartaigh, "Whitecaps and the passive remote sensing of the ocean surface," Int. J. Remote Sens., vol. 7, no. 5, pp. 627-642, May 1986.

[11] P. W. Gaiser, K. M. St. Germain, E. M. Twarog, G. A. Poe, W. Purdy, D. Richardson, W. Grossman, W. L. Jones, D. Spencer, G. Golba, J. Cleveland, L. Choy, R. M. Bevilacqua, and P. S. Chang, "The WindSat spaceborne polarimetric microwave radiometer: Sensor description and early orbit performance," IEEE Trans. Geosci. Remote Sens., vol. 42, no. 11, pp. 2347-2361, Nov. 2004.

[12] M. D. Anguelova, M. H. Bettenhausen, and P. W. Gaiser, "Passive remote sensing of sea foam using physically-based models," in Proc. IGARSS, Jul. 31-Aug. 4 2006, pp. 3676-3679.

[13] G. F. Williams, Jr., "Microwave emissivity measurements of bubbles and foam," IEEE Trans. Geosci. Electron., vol. GE-9, no. 4, pp. 221-224, Oct. 1971.

[14] Y. A. Militskii, V. Y. Raizer, E. A. Sharkov, and V. S. Etkin, "Thermal radio emission from foam structures," Sov. Phys.-Tech. Phys., vol. 23, no. 5, pp. 601-602, May 1978.

[15] W. E. Asher, Q. Wang, E. C. Monahan, and P. M. Smith, "Estimation of air-sea gas transfer velocities from apparent microwave brightness temperature," Mar. Technol. Soc. J., vol. 32, no. 2, pp. 32-40, 1998.

[16] L. A. Rose, W. E. Asher, S. C. Reising, P. W. Gaiser, K. M. St. Germain, D. J. Dowgiallo, K. A. Horgan, G. Farquharson, and E. J. Knapp, "Radiometric measurements of the microwave emissivity of foam," IEEE Trans. Geosci. Remote Sens., vol. 40, no. 12, pp. 2619-2625, Dec. 2002.

[17] W. Nordberg, J. Conaway, D. B. Ross, and T. T. Wilheit, "Measurements of microwave emission from a foam-covered, wind-driven sea," J. Atmos. Sci., vol. 28, no. 3, pp. 429-435, Apr. 1971

[18] W. J. Webster, T. T. Wilheit, D. B. Ross, and P. Gloersen, "Spectral characteristics of the microwave emission from a wind-driven foam-covered sea," J. Geophys. Res., vol. 81, no. 18, pp. 3095-3099, Jun. 1976.

[19] P. M. Smith, "The emissivity of sea foam at 19 and $37 \mathrm{GHz}$," IEEE Trans. Geosci. Remote Sens., vol. 26, no. 5, pp. 541-547, Sep. 1988.

[20] P. Pandey and R. Kakar, "An empirical microwave emissivity model for a foam-covered sea," IEEE J. Ocean. Eng., vol. OE-7, no. 3, pp. 135-140, Jul. 1982.

[21] F. Wentz, "A model function for ocean microwave brightness temperature," J. Geophys. Res., vol. 88, no. C3, pp. 1892-1908, Feb. 1983

[22] J. L. Franklin, "Tropical cyclone report: Hurricane Dean," Nat. Ocean. Atmos. Admin., Nat. Hurricane Center, Miami, FL, Apr. 2008.

[23] J. P. Bobak, D. J. Dowgiallo, N. R. McGlothlin, and K. M. St. Germain, "APMIR: Airborne Polarimetric Microwave Imaging Radiometer," in Proc. IGARSS, Sydney, Australia, 2001, pp. 505-507. DOI: 10.1109/IGARSS.2001.976204.

[24] W. K. Melville and P. Matusov, "Distribution of breaking waves at the ocean surface," Nature, vol. 417, no. 6884, pp. 58-63, May 2002.

[25] S. K. Friedlander, Smoke, Dust and Haze: Fundamentals of Aerosol Behavior. New York: Wiley, 1977.

[26] National Data Buoy Center (NDBC). [Online]. Available: http://www. ndbc.noaa.gov/

[27] National Centers for Environmental Prediction (NCEP). [Online]. Available: http://www.mmm.ucar.edu/mm5/mm5v3/data/gdas.html

[28] Y. Sugihara, H. Tsumori, T. Ohga, H. Yoshioka, and S. Serizawa, "Variation of whitecap coverage with wave-field conditions," J. Mar. Syst., vol. 66, no. 1-4, pp. 47-60, Jun. 2007.

[29] R. S. Bortkovskii, Air-Sea Exchange of Heat and Moisture During Storms. New York: Springer-Verlag, 1987.

[30] J. Wu, "Individual characteristics of whitecaps and volumetric description of bubbles," IEEE J. Ocean. Eng., vol. 17, no. 1, pp. 150-158, Jan. 1992.

[31] C. Ichoku, D. A. Chu, S. Mattoo, Y. J. Kaufman, L. A. Remer, D. Tanré, I. Slutsker, and B. N. Holben, "A spatio-temporal approach for global validation and analysis of MODIS aerosol products," Geophys. Res. Lett., vol. 29, no. 12, pp. MOD121-MOD124, Jun. 2002. DOI: 10.1029/2001GL013206.

[32] E. C. Monahan, "Occurrence and evolution of acoustically relevant subsurface bubble plumes and their associated, remotely monitorable, surface whitecaps," in Natural Physical Sources of Underwater Sound, B. R. Kerman, Ed. Norwell, MA: Kluwer, 1993, pp. 503-517.

[33] M. Stramska and T. Petelski, "Observations of oceanic whitecaps in the north polar waters of the Atlantic," J. Geophys. Res., vol. 108, no. C3, pp. 31-1-31-10, Mar. 2003.

[34] E. Hecht and A. Zajac, Optics. Reading, MA: Addison-Wesley, 1974.

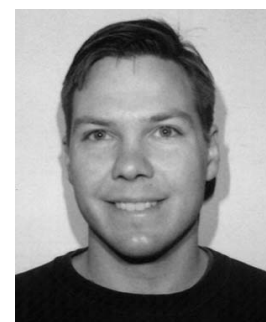

Justin P. Bobak (M'89) received the Ph.D. degree in electrical engineering from The Pennsylvania State University, University Park, in 1998. His thesis work was on modeling the effects of turbulence on water vapor radiometer measurements.

Since 1998, he has been with the U.S. Naval Research Laboratory, Washington, DC, first as a Contractor and, for the last ten years, as a Government Employee. As the Principal Investigator for the Airborne Polarimetric Microwave Imaging Radiometer (APMIR), he was the Technical Lead on the error budget, sensor design, and flight campaigns. In addition to the satellite calibration and validation flights by APMIR, he was involved in aircraft flights to retrieve soil moisture data in coordination with a ground-based Earth sampling team and flights to compare video and microwave responses of whitecaps. He has been involved in ground-based campaigns to measure polarimetric snow signature. Additional experiments have included wave-tank sensor installations on whitecaps and foam coverage, plus radio frequency interference signature detection flights for the charting of future satellite data corruption. He is currently working on error budgeting for the National Polar-orbiting Operational Environmental Satellite System Microwave Imager/Sounder radiometer.

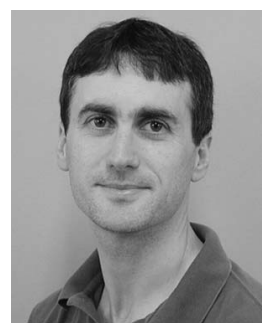

William E. Asher (M'06) received the B.A. degree in chemistry from Reed College, Portland, OR, in 1980 and the Ph.D. degree in environmental science and engineering from Oregon Graduate Institute for Science and Technology, Beaverton, in 1987.

$\mathrm{He}$ is currently a Principal Oceanographer with the Applied Physics Laboratory, University of Washington, Seattle, and a Senior Research Associate with the Department of Civil and Environmental Engineering, Portland State University, Portland. His research interests include breaking waves, air-water transfer processes, and modeling the formation of secondary organic aerosols. He is the Editor of Atmospheric Chemistry and Physics published by the European Geophysical Society.

Dr. Asher is a member of the IEEE Geoscience and Remote Sensing Society, the American Geophysical Union, and the American Chemical Society.

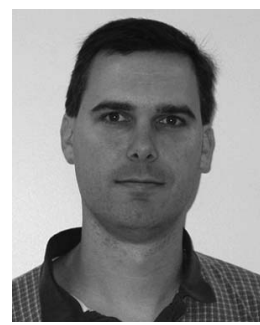

David J. Dowgiallo received the B.S. degree in electrical engineering from George Mason University, Fairfax, VA, in 2002

He is currently with the U.S. Naval Research Laboratory, Washington, DC. He has developed several radiometer systems that have been deployed by land, air, and sea, plus sensor contributions to the Navy's WindSat satellite program. He has participated in several field campaigns to gather data for various environments of radiometric interest, including snow, ice, foam, and high wind/ocean interaction (hurricane flights). His current focus has been on aircraft-based interferometer systems, consisting of extended baseline arrays and software-implemented correlators.

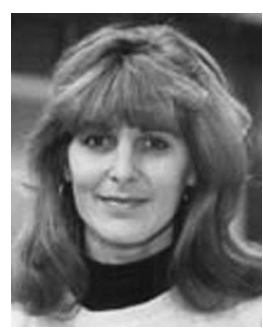

Magdalena D. Anguelova received the B.S. degree in engineering physics from the University of Sofia, Sofia, Bulgaria, in 1984 and the M.S. and Ph.D. degrees in oceanography from the University of Delaware, Newark, in 1997 and 2002, respectively.

Her background in remote sensing is based on atmospheric pollution monitoring using diode lasers and developing of optical schemes for coherent Doppler lidar for measuring wind speed and direction in the atmosphere in the Institute of Electronics, Bulgarian Academy of Sciences, Sofia, from 1984 to 1994. She joined the Remote Sensing Division, U.S. Naval Research Laboratory, Washington, DC, in 2002, as a National Research Council (NRC) Postdoctoral Fellow. Her current research interests include the development and improvement of satellite-based whitecap fraction, its use for parameterizations of various air-sea interaction processes, breaking waves, bubbles and bubble clouds, and sea-spray aerosols. 